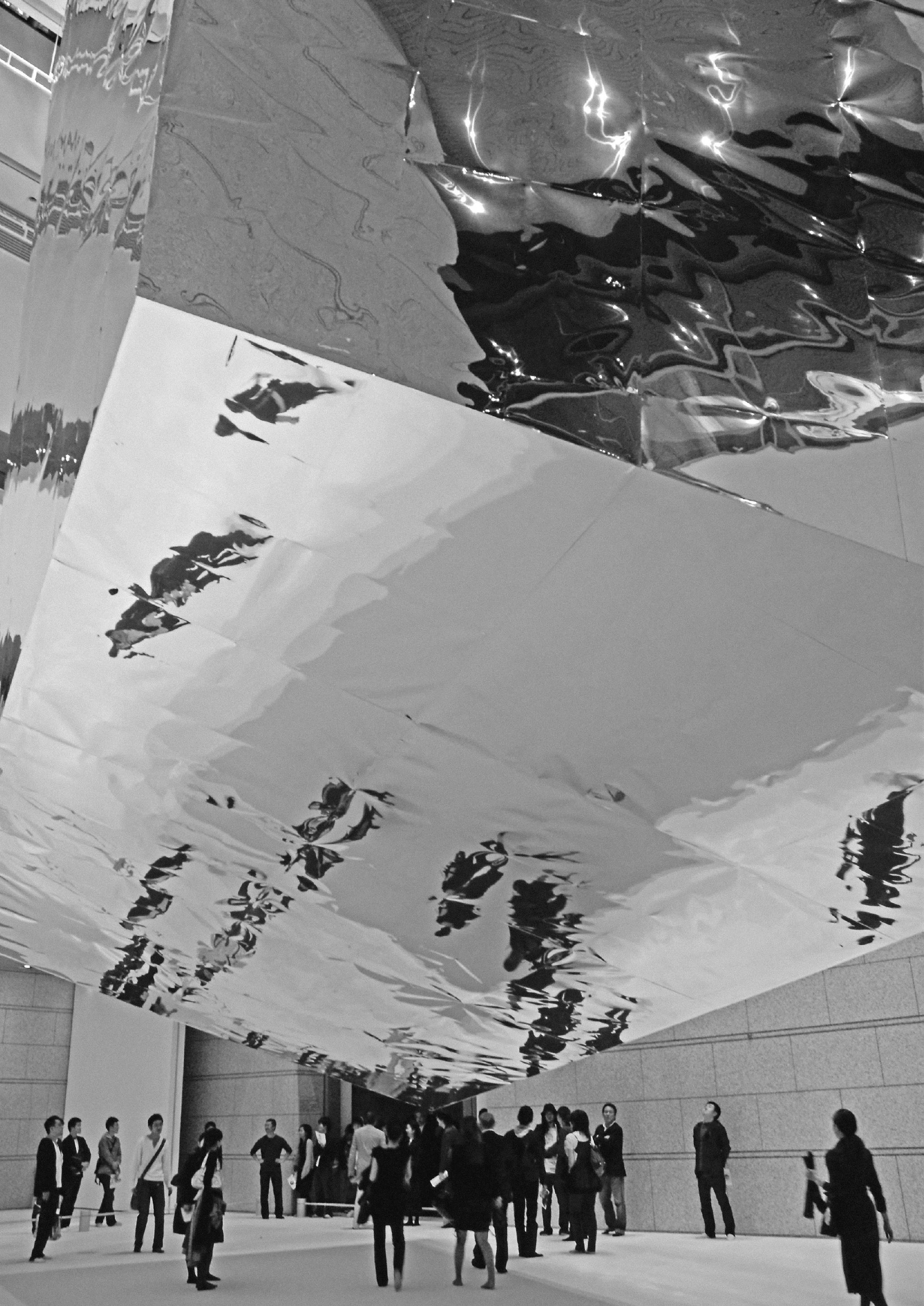




\section{The limits of materiality: On Junya Ishigami and Philippe Rahm}

Tom Daniell

If architecture arose from the necessity of creating shelter, then it might be regarded as essentially the arrangement of more-or-less rigid, opaque materials to form more-or-less hermetic containers. At a more abstract level, to see architecture solely in terms of shelter implies that it is essentially a means of making the natural environment more hospitable, or a method to increase the range of natural climatic conditions within which humans can realistically survive - much like clothing or air-conditioning. In his 1969 book The Architecture of the WellTempered Environment, Reyner Banham contrasted two ways in which a "savage tribe" might exploit the environmental potential of fallen timber on a cold night: to build a shelter, or to make a fire. Taking these as two archetypal extremes on the spectrum of architectural possibilities - form versus energy, material versus immaterial - we can find contemporary analogues in the work of Japanese architect Junya Ishigami and Swiss architect Philippe Rahm. Both attempt to trace and manifest the performative and physical limits of the architectural enclosure. In Banham's parable, Ishigami would attempt to discover the minimum thicknesses and maximum spans of which the wood is capable, whereas Rahm would exploit the potentials of combustion and smoke.

A former apprentice of SANAA, Ishigami creates objects that transcend the categories of furniture, sculpture, installation, and building. They comprise elements that seem suspended or merely touching, lacking any plausible means of support. This is structural exhibitionism by omission - not the manifest agility of a gymnast, but the illusions of a stage magician. From his 2004 debut Table (a thin sheet of steel made to span nine metres by giving it a pre-stressed camber that settles flat under its own weight), to the 2007 installation Balloon (a one-tonne armature of aluminium framing and skin made weightless with precisely the right amount of helium), to the 2008 KAIT building (an almost-flat roof sitting on a forest of thin
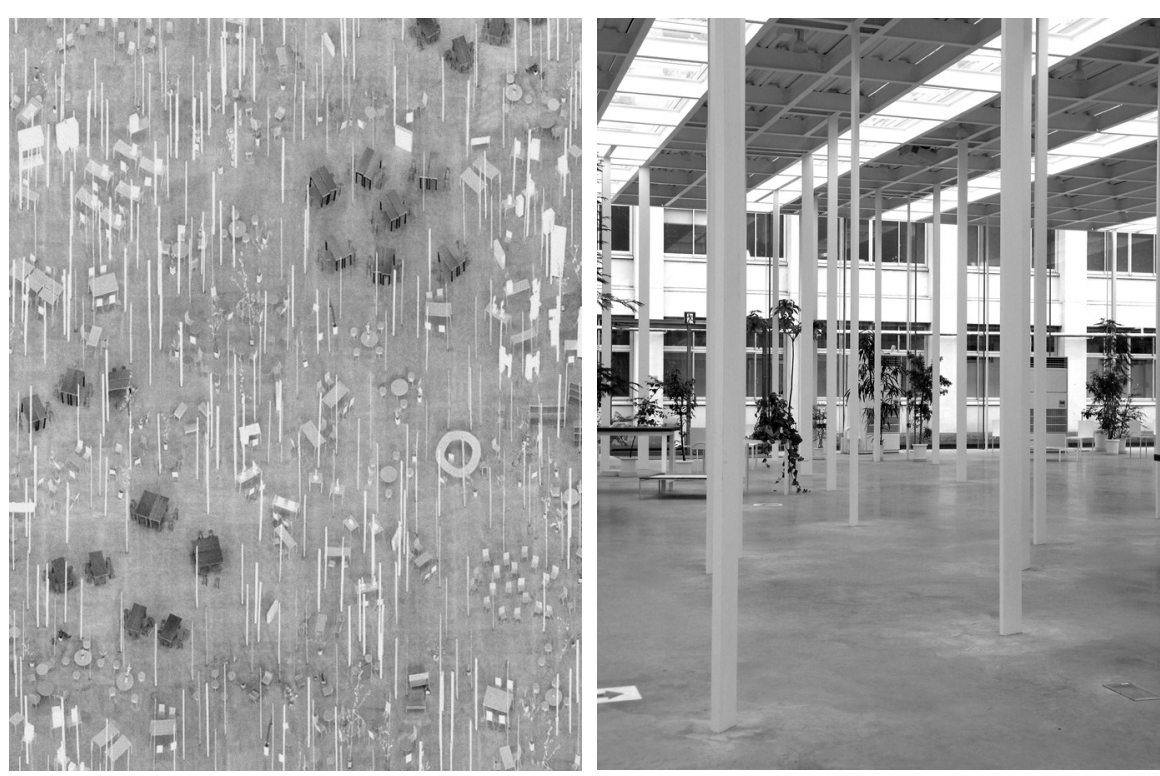

Fig. 1 (opposite page) Junya Ishigami, 2008. Balloon, Tokyo, Japan. A frame and skin made of aluminium weighing one tonne, but filled with precisely enough helium to make it as light as air. [Photo: Courtesy Junya Ishigami, 2008]

Fig. 2 (left) Junya Ishigami, 2008. KAIT Workshop, Kanagawa, Japan (model). [Photo: Courtesy Junya Ishigami, 2008] Fig. 3 (right)Junya Ishigami, 2008. KAIT Workshop, Kanagawa, Japan (interior). A glass-clad student hall with a flat roof supported by an array of thin white steel bars, some in compression and others in tension. [Photo: Courtesy Junya Ishigami, 2008] 
Fig 4. Philippe Rahm, 2012. Evaporated Rooms, Lyons, France.

An apartment refurbishment designed around naturally occurring atmospheric gradations of humidity. [Photo: courtesy Philippe Rahm 2012]

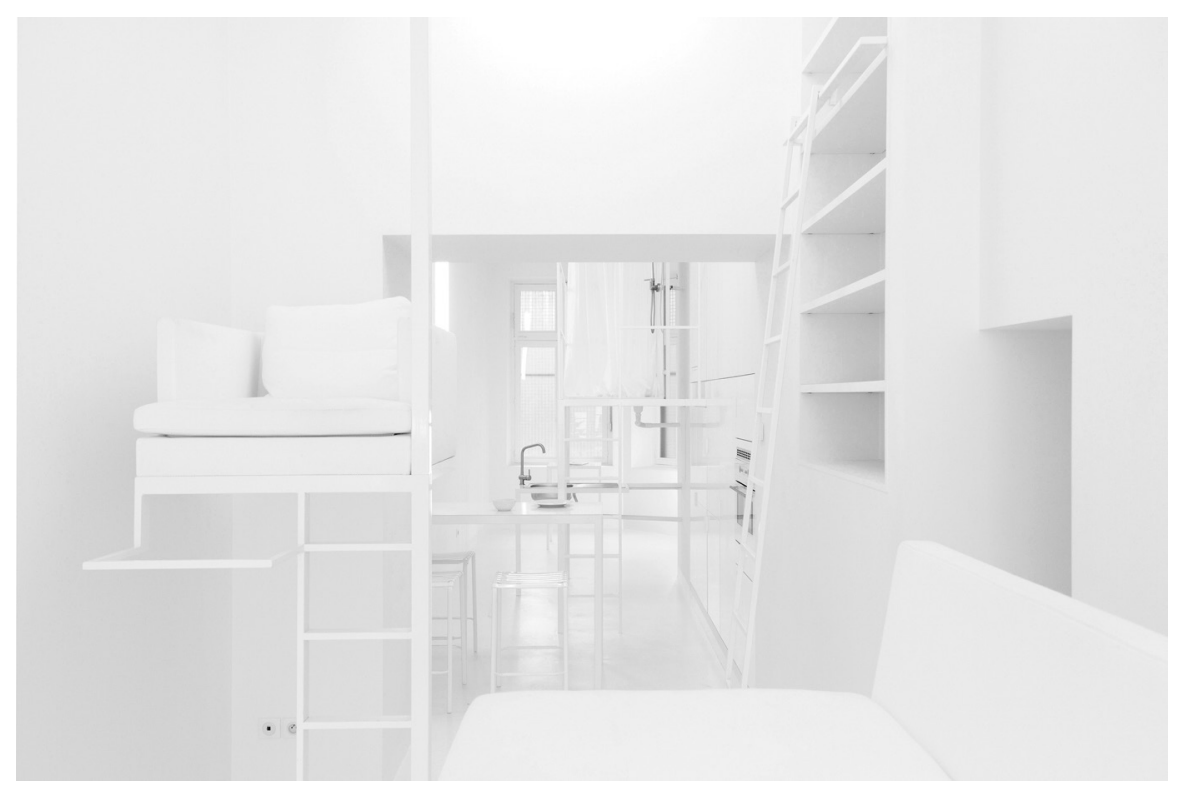

steel bars, their orientation and thickness cumulatively strong enough to support it, but only just), Ishigami's work is a didactic demonstration of the limits of material performance. Indeed, he has at least once crossed the line, with the collapse of his barely-visible carbon fibre installation at the 2010 Venice Biennale. The more extraordinary the effect, the less noticeable it is - his house proposals seem to leave the surfaces of their sites untouched, like fragile open-topped boxes turned upside down and placed lightly on the ground, giving no hint of the sophisticated foundation systems that this entails.

Drawing on the ecological insights of Banham and the pneumatic architectural experiments of the 1960s, Rahm produces nuanced physiological effects that act on the skin ahead of the eyes, categorising his work with terms more common in mechanical engineering than architectural design: radiation, conduction, convection, pressure, evaporation, digestion. Passive and active climate-control techniques that are conventionally used to produce homogeneous interior environments are deployed to create experiential variety in illumination, temperature and humidity instead. Architectural design has always been about the creation of appropriate moods, but Rahm operates directly on the atmosphere (understood in material, not metaphorical, terms), which drives the composition and performance of the physical building envelope. Despite the relatively simple, box-like appearance of the buildings, they are experienced as amorphous fields, shifting clouds of delicately varying ambience.

One might see these two approaches as polar opposites, or as tending toward the same asymptote at which architecture vanishes. Ishigami reduces tectonics to graphics, structure to calligraphy, and spatial boundaries to the thinnest, lightest, or most transparent condition possible. Rahm entirely dissolves spatial boundaries into graduated fields of heat, light, or moisture. Yet both reveal the tension inherent in any apparent stability in architecture. The reductive clarity of all this work provides stark and beautiful, demonstrations of two of the most fundamental and unavoidable necessities for all buildings: to brace against imminent collapse, and to constantly replenish lost energy. 


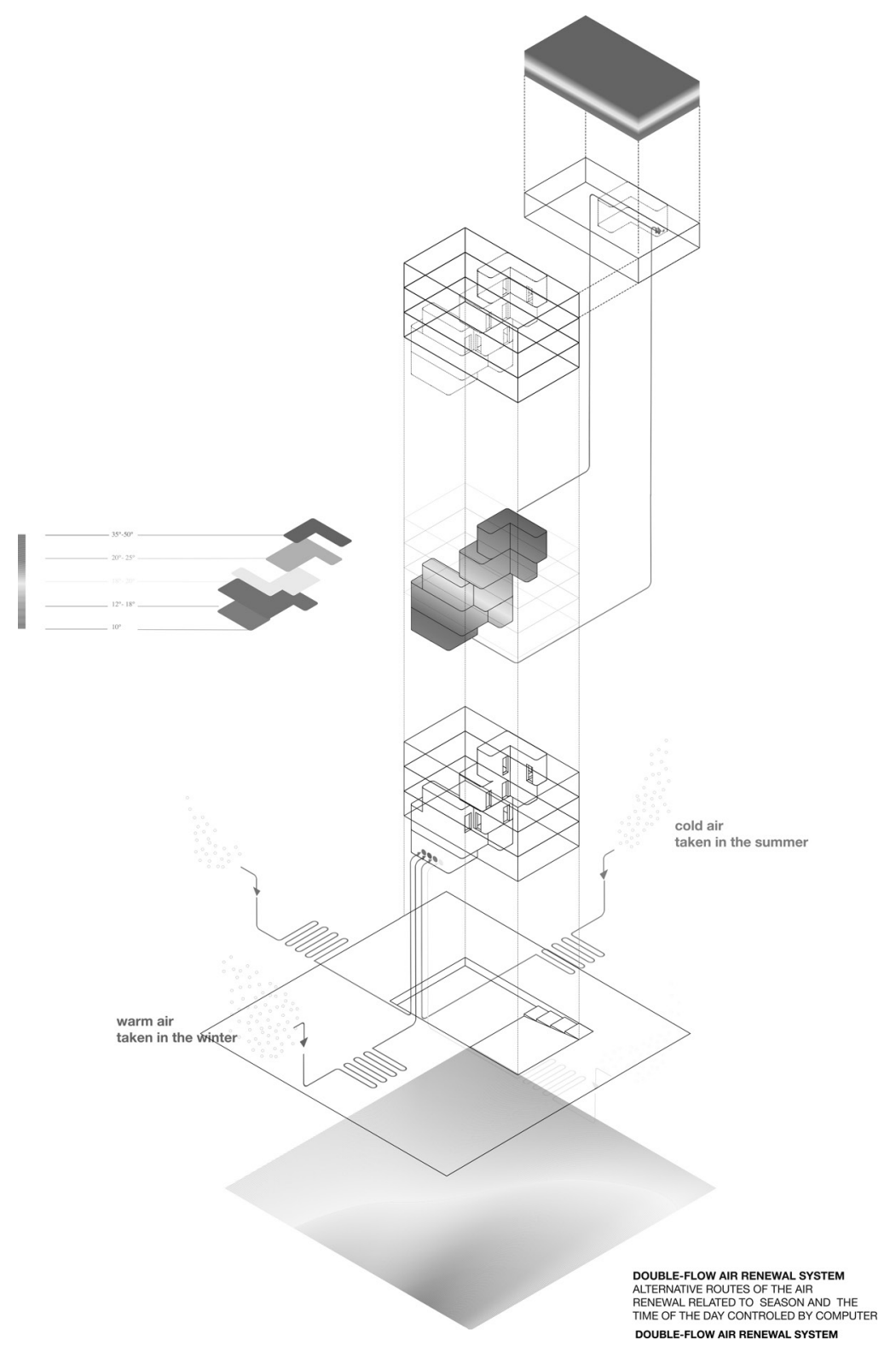

Fig 5. Philippe Rahm, 2009. Convective Condominium, Hamburg, Germany.

An apartment designed with terraced floor slabs and differing ceiling heights to create a varied thermal landscape. [Photo: courtesy Philippe Rahm 2009] 